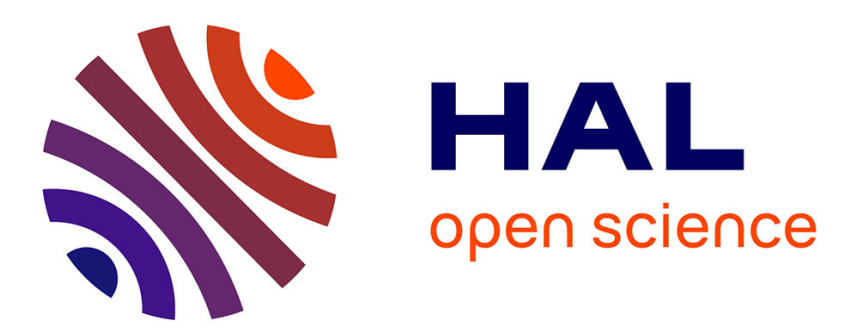

\title{
Experimental and Numerical Investigation of the Silicon Particle Distribution in Electrospun Nanofibers
}

Saja Al-Ajrash, Khalid Lafdi, Erick Vasquez, Francisco Chinesta, Philippe Le Coustumer

\section{- To cite this version:}

Saja Al-Ajrash, Khalid Lafdi, Erick Vasquez, Francisco Chinesta, Philippe Le Coustumer. Experimental and Numerical Investigation of the Silicon Particle Distribution in Electrospun Nanofibers. Langmuir, 2018, 34 (24), pp.7147-7152. 10.1021/acs.langmuir.8b01167 . hal-01829949

\section{HAL Id: hal-01829949 \\ https://hal.science/hal-01829949}

Submitted on 22 Sep 2018

HAL is a multi-disciplinary open access archive for the deposit and dissemination of scientific research documents, whether they are published or not. The documents may come from teaching and research institutions in France or abroad, or from public or private research centers.
L'archive ouverte pluridisciplinaire HAL, est destinée au dépôt et à la diffusion de documents scientifiques de niveau recherche, publiés ou non, émanant des établissements d'enseignement et de recherche français ou étrangers, des laboratoires publics ou privés. 


\title{
Experimental and numerical investigation of the Silicon particle distribution in electro-spun nano-fibers
}

\author{
Saja M Nabat Al-Ajrash*, Khalid Lafdi*, Erick S. Vasquez*, Francisco Chinesta**, and \\ Philippe Le Coustumer*** \\ *University of Dayton, 300 College Park, Dayton Ohio 45469 USA \\ ** Centrale Nantes, 1 rue de la Noe, BP 92101, 44321 Nantes Cedex 3, France \\ *** University of Bordeaux, UF STE, B.18 Allée G. Saint/Hilaire \\ CS 50023, 33615 Pessac Cedex, France
}

\begin{abstract}
The properties of ceramic materials are dependent on crystal size and their distribution. These parameters can be controlled using electrospinning of the two/phase mixed system. The pre/ ceramic solution consists of silicon nano/particles and polyacrylonitrile (PAN) polymer mixture. Particles distribution during the electrospinning technique was characterized using TEM microscopy and modeled using Finite Element Method (FEM). The experimental and numerical results were in agreement. Large silicon particles were located in the skin and the smaller ones were located at the core. This illustrated by the migration rate from the core which was the fastest for large particles and it diminished as the particles become smaller in size. The threshold for Stokes number was found to be around 2.2E-4 with a critical particle size of $1.0 \mathrm{E} 7 \mathrm{~m}$ in diameter. The current results are very promising, as it demonstrated a novel way for the fabrication of PAN/Si ceramic nano/fibers with a gradient of particle size and properties from the skin to the core.
\end{abstract}

\section{Introduction}

One of the vital research areas in fiber fabrication is spinning of a colloidal system which consists of polymer and nanoparticles to fabricate a multi/component nano/fibers. The incorporation of inorganic materials into organic precursors to produce a hybrid composites lead to new material properties [1]. Silicon and silicon oxide are considered to be a significant nanoparticles, which can be embedded in the polymer solution to achieve new hybrid material [2]. For instance, carbon/silicon (C/Si) composite nanofibers can be prepared by a judicious combination of colloid 
electrospinning and subsequent thermal treatments. As a result, it is possible to tailor properties with various particles that ultimately will be transformed into a gradient of crystal size. For example, the oxidation resistance of silicon carbide ( $\mathrm{SiC})$ is dependent on its particles size [3, 4]. Quanli et al [5] confirmed that silicon carbides particles have a massive effect on oxidation kinetics, as the weight gain and rate constant were inversely related to $\mathrm{SiC}$ particles size. In addition, they observed that the oxidation temperature had increased by changing the particle size from nano to micrometric scale.

The dispersion, miscibility, and particle location inside the fibers are limiting factors in determining the final fiber properties [6]. The process needs to be very well understood and controlled. The general protocol to control particles distribution falls into two main categories: active and passive particles distribution [7, 8]. The first group is based on directing external sources of energy to regulate the particle trajectories. These sources involve a dielectrophoresis (DEP) [9], electrophoresis [10], acoustic, optical fractionation $[11,12]$, magnetic $[13,14]$, electric, and thermal ones [15]. For example, in electrospinning, the electric forces can effect on charged elements distribution. Furthermore, the surface and core properties can be tailored to fit different applications by monitoring the species charge. Sun et al [16] investigated two polymer components distribution within the electrospun fibers. One of the components was neutral (polyethylene oxide (PEO)) while the other one was charged (peptide/ polymer conjugate). The results showed that the outer surface collected the charged peptide, and the PEO was localized in the fiber center. In addition, Biono [17] used alginate and PEO blends to investigate components segregation during electrospinning process. The observations showed that negatively charged alginate clustered on the wall while the PEO was concentrated at the core.

On the other hand, a passive separation which based on morphological variations between particle groups like (shape, size, deformability, and mass) was used to isolate the particles by utilizing inertial forces or hydrodynamic effect [18, 7, 19]. It is very important to study and control this separation category as it is responsible for clustering the particles according to their size, which is very crucial in controlling the final fiber properties. Szczech and Jin [20] manipulated reversible capacity values in 
lithium/ion batteries by changing silicon particle size. As a result, the accumulation of big or small particles at the wall seems to lead to different electrochemical properties. To perform the separation, Park et al [21] utilized inertial forces to isolate a multi/sized spherical particles which flowing in a series of the microchannels. As a result of initial forces, the particles bent from the main fluid streamlines and accumulated on the channel walls. Furthermore, Bec [22] found a critical value for Stokes number in which the particles began to cluster. The threshold for this number was around $10^{14}$ and below this number, no particle separation occurred.

Controlling the double/phase dispersion in the nano/scale is very challenging. One method is using electrospinning technique, which is an easy and reliable method for the fabrication of nanofibers [23]. In this process, the electrical field has the functionality of inducing electrical charge along the liquid surface. Increasing the intensity of the electrical field, induce a Taylor cone as a result of elongation of the semicircular surface of the solution [24]. The electrospinning apparatus involves high voltage power supply $(1 / 30 \mathrm{KV})$, a syringe, needle, which connected to a terminal, and collector which connected to the ground [25]. To fabricate ceramics or carbon nanofibers, electrospinning has been extensively utilized in recent years [26, 27, 28, 29, 30, 31]. In this method, fiber with sizes from sub/microns to few nanometers can be fabricated $[32,33,34,35]$. To fabricate successful fibers, several factors can be related to properties and morphology of the spun fibers; for instance, solution concentration, molecular mass, rheology, molecular alignment and electrical conductivity play a vital role in this process [36, 37]. Kim and Um [38] investigated the influence of the electrospinning parameters on silk fibroin (SF) nanofibers properties. The effect of the concentration and viscosity showed a dominant role in defining the fiber morphology and defect formation. They found that the viscosity threshold to fabricate a bead free fibers was around 0.13 and 0.2 P.s. In addition, the authors showed that increasing the silk concentration resulted in increasing the diameter of the fiber [14]. Mit/uppatham et al [39] studied the effect of polymer molecular weight, concentration, and viscosity on ultra/fine polyamide/6 (PA/6) fibers. Their results showed a monotonic increase in fibers diameter that occurred with increasing the polymer viscosity and concentration. 
In this work, electrospinning technique was utilized to fabricate hybrid nano/ fibers. The main polymer was Polyacrylonitrile (PAN) which mixed with silicon nano/ particles with very low percentages to form the colloidal solution. The effect of silicon percentage on fiber morphologies was examined using Scanning Electron Microscope (SEM). As the silicon particles are neutral, the active separation is not possible and the passive one is dominant. The particle size distribution inside the fiber was characterized using Transmission Electron Microscope (TEM) and numerically using software package COMSOL Multiphysics Version 5.

\section{Experimental procedure}

The electrospinning solution was prepared by dissolving PAN ( $\mathrm{Mn}=100,000 \mathrm{~g} \mathrm{~mol}^{1 /}$ ) which purchased from Scientific Polymer Inc. Ontario, NY) and Si nanoparticles with average size of $200 \mathrm{~nm}$ (Sky Spring Inc. Houston, TX) in $10 \mathrm{ml} \mathrm{N}, \mathrm{N}$ - Dimethylformamide (DMF). The weight percentages of the solution components were $10 \mathrm{wt} \%$ of PAN and $\mathrm{Si}$, and $90 \mathrm{wt} \% \mathrm{DMF}$. The weight contents of Si and PAN in each sample are listed in Table 1.

Table 1

PAN to Si ratios.

Sample PAN wt $\%$ Si wt $\%$

PAN10 $10 \quad 0$

PAN9.95 $9.95 \quad 0.05$

PAN9.9 $9.9 \quad 0.1$

PAN9.5 $9.5 \quad 0.5$

PAN9 $9 \quad 1$

The mixture was vigorously stirred using a magnetic agitator at $60{ }^{\circ} \mathrm{C}$ for 8 hours until $\mathrm{Si}$ and PAN were fully mixed. Then, the mixture was loaded to electrospinning apparatus to produce nano/fibers. The electrospinning setup is composed of a voltage controller (Stanford research systems, Inc. Model P.S375, Sunnyvale, CA), a syringe pump (New Era Pump Systems, Inc., NE-300, Farmingdale, NY), rotating collector (Dayton ${ }^{\circledR}$ DC Motor, 4Z145). A voltage of $15 \mathrm{kV}$ was applied to the solution to start the spinning process. The electrospun fibers were collected on a rotating drum. Finally, he feeding rate for all samples was around $0.003 \mathrm{ml} \mathrm{min}$. The distance between the syringe tip and the collector was $25 \mathrm{~cm}$.

Scanning Electron Microscope (SEM, ProX, Phenom, Eindhoen, Netherlands) was utilized to characterize the morphology of the fibers. To estimate the average fibers diameter, 
about 50 fibers were measured randomly using Image $\mathrm{J}$ software [40]. TEM was utilized to track particles distribution within the fiber. Finally, to find fluid rheological properties, Anton Paar MCR/302 Modular Compact Rheometer was used to find the fluid viscosity.

\section{Modeling}

COMSOL Multiphysics Version 5 was selected to simulate silicon particle size distributions within electro/spun fibers. Due to the difficulty of including the whole electrospinning machine, a small part of the fiber was included by representing it in 2/D symmetric geometry (to reduce the computational cost). The modeled part was taken from the stable straight jet to avoid electrohydrodynamic instabilities in whipping and to ensure that most of the solvent still in place which means that the solution is almost fluid. One of the challenges in modeling such process is that everything in electrospinning is in macro/scale while the fibers and particles in micro/scale to nano/scale. In this model, the main fluid (PAN/DMF solution) flow was modeled using laminar flow module and the particle position with time was tracked using the particle tracing module. The electric field effect on particle position was neglected, due to the neutral nature of silicon nano/ particles. Finally, solvent evaporation was considered as a neglible in this model.

\section{Meshing}

Triangular and quadrilateral mesh types (Figure 1) with total 90460 elements were used to divide the computational domain. The elements size and type were selected after performing the Grid refinement study. 


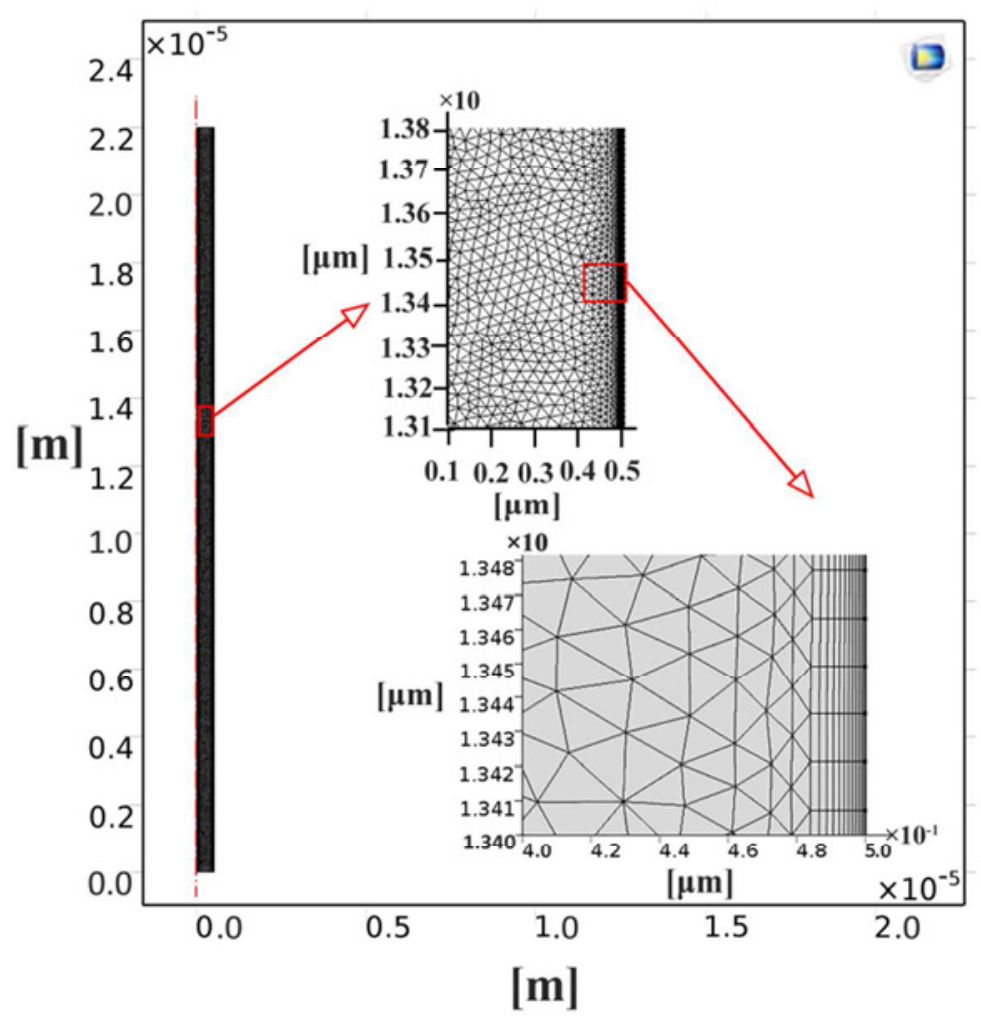

Figure 1: mesh generation

\section{Governing equations}

The fluid flow inside the computational domain is governed by the Navier/Stokes equation which solves the conservation of momentum and the continuity equation for conservation of mass. This equation for incompressible and stationery flow [41] can be simplified as:

$$
\begin{aligned}
& \rho(u \cdot \nabla) u=\nabla \cdot\left[-\mathrm{PI}+\mu\left(\nabla u+(\nabla u)^{T}\right)\right]+\mathrm{F} \\
& \rho \nabla \cdot(u)=0
\end{aligned}
$$

Where $\rho$ is the fluid density (978 $\mathrm{kg} \cdot \mathrm{m}^{/ 3}$ ) which calculated using mixture law and $\mu$ is the dynamic viscosity (0.175 Pa.s). In addition, to find the fluid velocity (u), the volumetric flow rate $(\mathrm{Q})$ which is known from the pump that connected to the syringe is used as the follow [42, 43]:

$$
Q=\pi r^{2} u
$$

Where $\mathrm{r}$ is the fiber radius, $\mathrm{u}$ is the jet velocity, and after the calculations, the fluid velocity was found around $15 \mathrm{~ms}^{1}$. For the boundary conditions, the velocity is considered as a normal inlet velocity. Furthermore, due to the absence of the solid/liquid boundary and all the computational domain was fluid, the wall boundary condition was chosen as a slip wall. 
To find the particle position with time, the particle tracing for the fluid flow module was used. The governing equation [44] for such modules is:

$$
\frac{d}{d t}\left(m_{p} v\right)=F_{T}
$$

Where $m_{p}$ is the particle mass $(\mathrm{kg}), v$ : particle velocity $\left(\mathrm{ms}^{11}\right)$, and $F_{T}$ : total force $(\mathrm{N})$ The total force in our modeling is a combination of drag and inertial forces. The drag force (equation 5) is built - in force in the module [44]:

$$
F_{D}=\frac{1}{\tau_{p}} m_{p}(u-v)
$$

$\tau_{p}$ : Particle velocity response time for spherical particles in a laminar flow

$$
\tau_{p}=\frac{d_{p} \rho_{p}}{18 \mu}
$$

$d_{p}$ : is the particle diameter $(\mathrm{m})$, and $\rho_{p}$ is the particle density $\left(2328 \mathrm{~kg} / \mathrm{m}^{3}\right)$, and $\mathrm{u}$ is fluid velocity

The inertial force $[21,45]$ that controls the lateral/particles migration is defined using user/defined force in COMSOL.

$$
F_{i}=\frac{\pi U^{2} \rho_{p} d_{p}^{3}}{6 D_{h}}
$$

Where $F_{i}$ : Inertial force, $\mathrm{U}$ : average fluid velocity, and $D_{h}$ is the characteristic channel dimension. Although the behavior of heavy particles in micro fluids not totally understood [45], fluid and particles actions inside the microfibers can be analyzed using dimensionless numbers. For instance, the dimensionless number that controls the inertial and viscous forces [21] is the Reynolds number (Re). Another critical number is Stokes number ( $\mathrm{St}$ ) which defined as the ratio of particle relaxation time $\tau_{p}$ to flow characteristic time $\tau_{f}[21]$ as follow:

$$
S_{t}=\frac{\tau_{p}}{\tau_{f}}=\frac{\rho_{p} d^{2} / 18 \mu}{D_{h} / U_{m}}
$$

\section{Results and discussions}

\section{SEM characterization}

The SEM images of the as/spun nano/fibers with various Si weight percentages are shown in Figure 2 

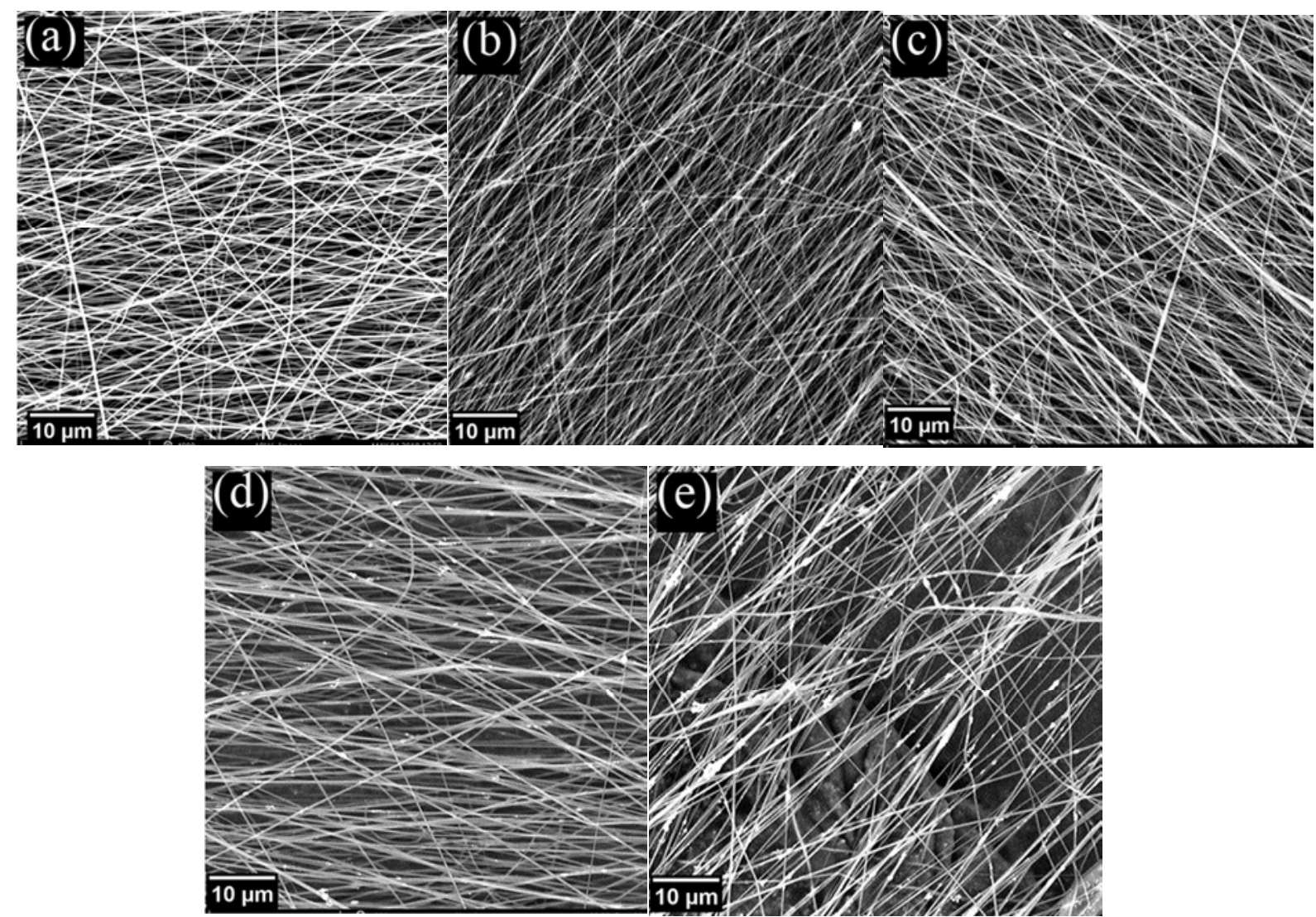

Figure 2: SEM micrograph for a): $10 \% \mathrm{PAN}, \mathrm{b}): 9.95 \% \mathrm{PAN} / 0.05 \% \mathrm{Si}$, c): $9.9 \% \mathrm{PAN} / 0.1 \% \mathrm{Si}$, d): $9.5 \% \mathrm{PAN} / 0.5 \% \mathrm{Si}$, e): $9 \% \mathrm{PAN} / 1 \% \mathrm{Si}$.

For all concentrations, the resulted fibers were very uniform with limited defects like beads or surface irregularities. However, for fibers made with higher silicon contents (Figure 2 (d) and (e)) the resulted fibers show a noticeable amount of silicon particles on fiber surface which led to a rough fiber surface. Another effect of silicon content on fibers morphology was the fibers dimensional change (Figure 3). 


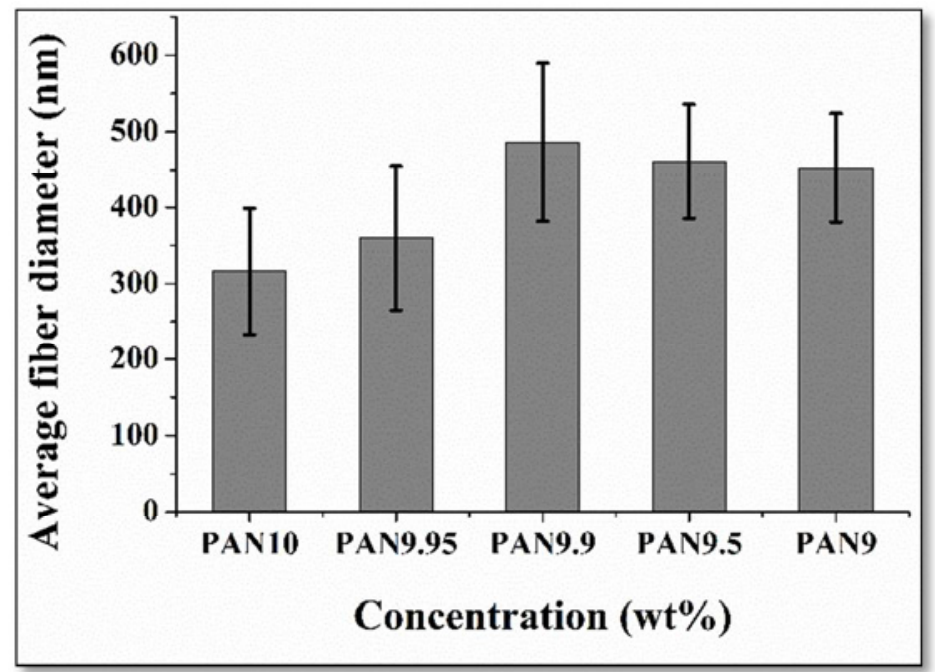

Figure 3: Silicon concentration effect on fiber average diameter.

Although the total solid content was kept constant (10 wt\%), the PAN/Si ratio showed a vital role in controlling the fiber diameter. The fiber diameter of PAN 9.95 showed around $14 \%$ increase as compared with PAN10. In addition, bigger fibers were fabricated using PAN9.9 which has $0.1 \mathrm{wt} \%$ of silicon. Further increase in Si content showed an adverse effect on fibers diameter [46, 47] as illustrated in Figure 3. These morphological changes were controlled by the polymer concentration which regulates the solution viscosity.

\section{TEM characterization}

The ultra/microtomy technique was performed for TEM sample preparation. TEM was used to characterize the particle size distribution in the fiber. The analysis was carried out for the fibers with $0.1 \mathrm{wt} \% \mathrm{Si}$ and $9.9 \mathrm{wt} \% \mathrm{PAN}$ as shown in Figure 4. 


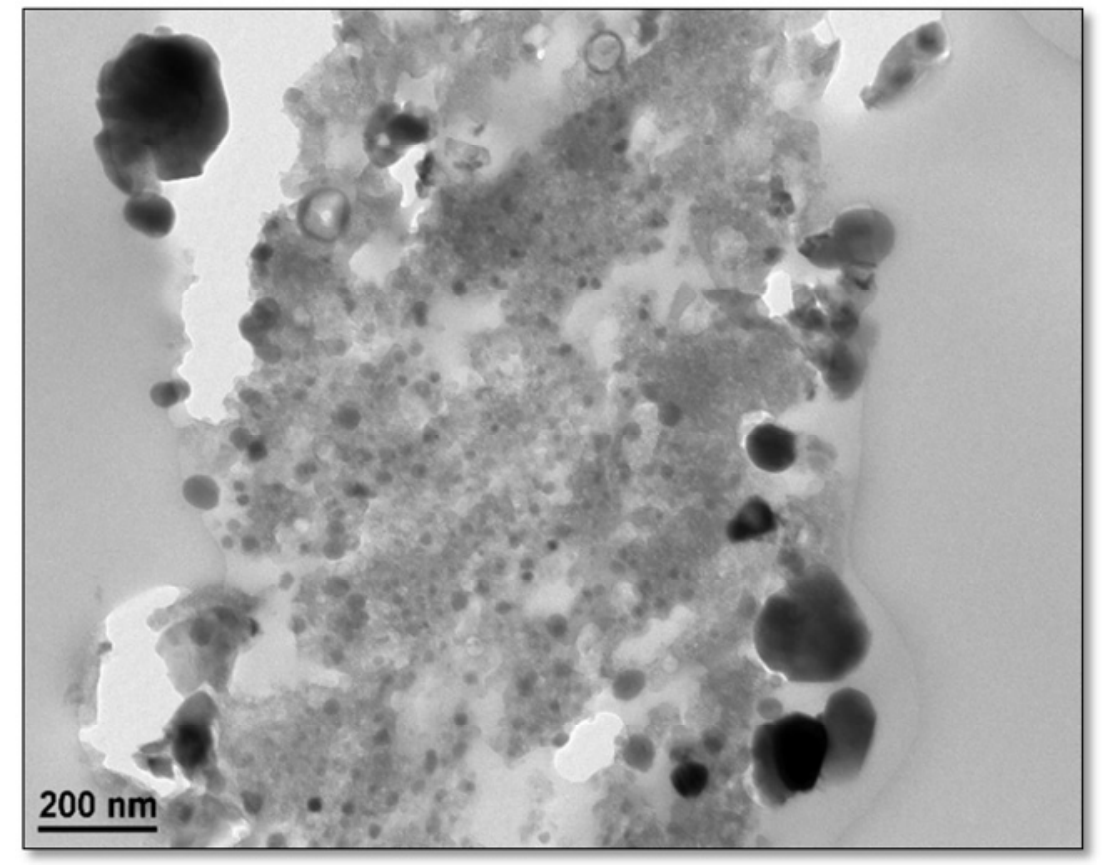

Figure 4: TEM image of fiber with $9.9 \% \mathrm{PAN} / 0.1 \% \mathrm{Si}$

From the above Figure, it is very obvious that silicon large particles were located near the wall and small particles were evenly distributed. This result was analyzed and confirmed using COMSOL multi/physics modeling by tracking the particle position with time.

\section{Modeling results}

\section{Visualization of Particle Distribution}

Particles with a varying size between $2.5 \mathrm{E}-7 \mathrm{~m}$ to $1.0 \mathrm{E}-8 \mathrm{~m}$ were used to understand the particle lateral migration under the influence of drag and inertial forces. A fluid with 9.9 wt $\%$ PAN and $90 \mathrm{wt} \%$ DMF was the carrier fluid. The velocity profile of this fluid was a uniform with $15 \mathrm{~m} . \mathrm{s}^{\prime 1}$ which results from setting the slip wall boundary condition. After solving the governing equations that mentioned earlier, the visualization of two particles set $(2.5 \mathrm{E}-7 \mathrm{~m}$ and $1.0 \mathrm{E}-8 \mathrm{~m}$ ) with different times is shown in Figure 5 (a) to (e). The big and small particles at the beginning of the release (Figure 5 (a)) have almost the same position without lateral movement. After spending the particles short time in vertical movement, the particle size effect began to be obvious. At 6.6 E-7s the big particles start to hit the wall (Figure 5 (c)) while the small ones kept flowing with the fluid main streamlines. After bumping the wall, the big particles freeze and solidify on it (Figure $5(\mathrm{~d})$ ) which solve the clue of populating the big particles on the wall. Finally, most of the big particles concentrated on the wall after spending 9.6E-6s (Figure 5(f)). 


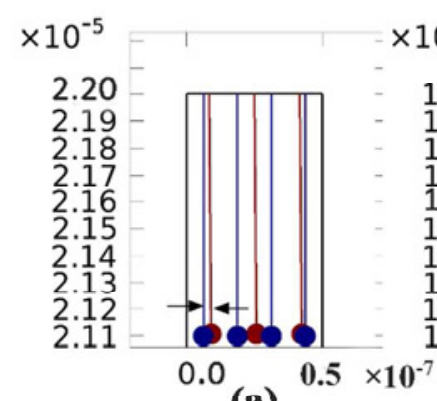

(a)

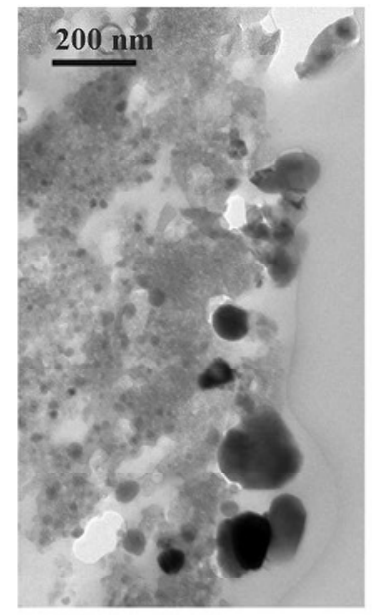

(e)

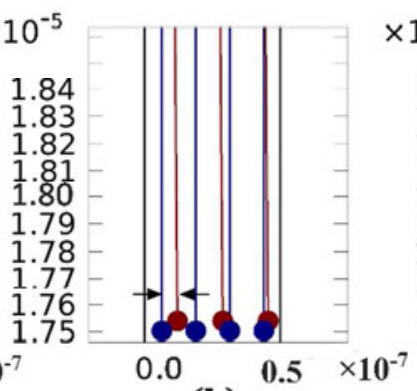

(b)

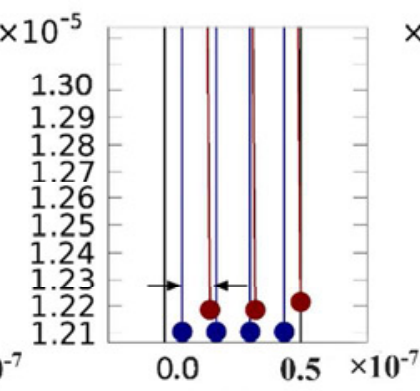

(c)

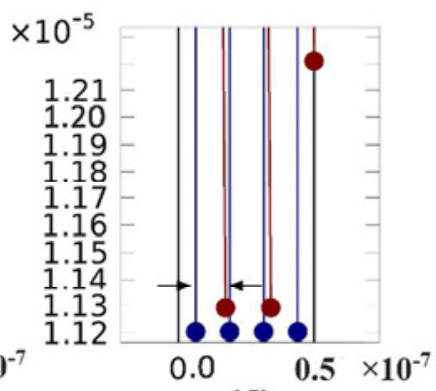

(d)

Time $=9.6 \mathrm{E}-6 \mathrm{~s}$ particle trajectories

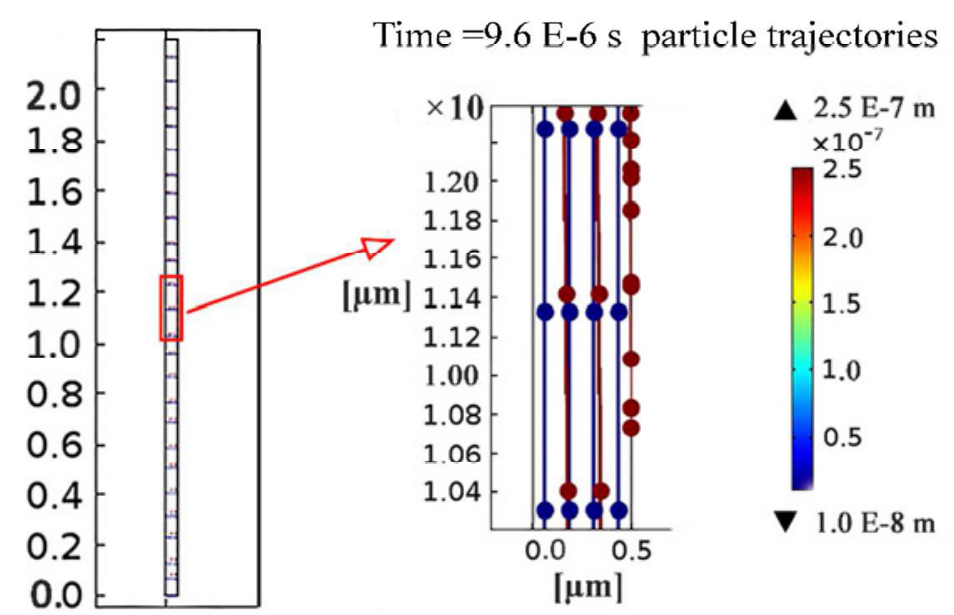

(f)

Figure 5: particles position from inlet at different times: (a) $6.0 \mathrm{E} / 8 \mathrm{~s}$ (b), $3.0 \mathrm{E} / 7 \mathrm{~s}$ (c), 6.6E/7s (d), 7.2E/7s (e) TEM image for the right side of the fiber (f), $9.6 \mathrm{E} / 6 \mathrm{~s}$

To sum up, the particles clustering on the wall were possible only for the big particle as the small particle confirmed a negligible transverse movement. Such behavior can be related to a distinctive particle inertial force for different sized particles. For big particles, the inertial effect was sufficient to enable the large particles to cross the fluid main streamlines.

Figure 6 illustrates the effect of particle size on transverse shift for five particles size group. From this Figure, it is very obvious that at the beginning of the electrospinning (time = 0 ), different particles with different dimensions were distributed randomly throughout the fiber. At that time, the smallet particle $1.0 \mathrm{E}-8$ has position around $0.44 \mu \mathrm{m}$ from the fiber centerline, while the largest particle has postion around $(0.38 \mu \mathrm{m})$. After a short time, particles with diameters ranging between $2.5 \mathrm{E}-7 \mathrm{~m}$ to $1.0 \mathrm{E}-8 \mathrm{~m}$ had different migration rates due to changes in inertial forces. For example, the largest particles in this model $(2.5 \mathrm{E}-7 \mathrm{~m})$ took about $0.66 \mu \mathrm{sec}$ to reach the wall and settle down on it, while the smallest particles $(1.0 \mathrm{E}-8 \mathrm{~m})$ followed the fluid 
inward velocity with negligible transverse movement. These numerical results were in agreement with various TEM characterizations (Figure 4).

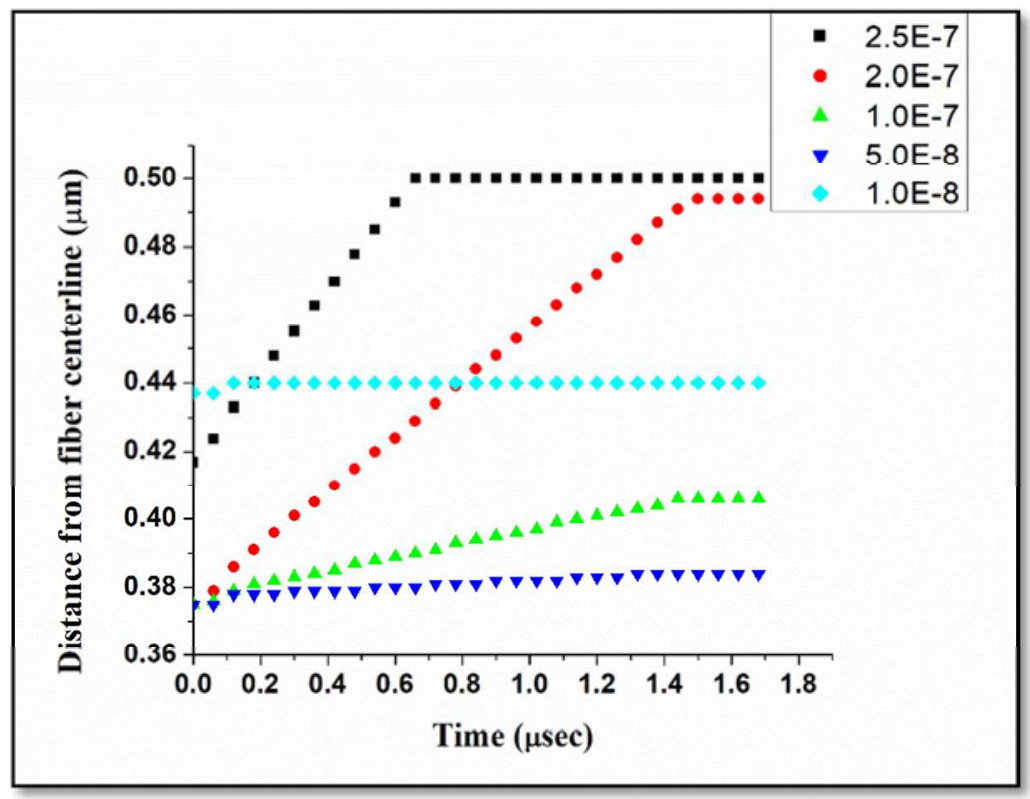

Figure 6: Particles position with time for a range of particles

From the above Figure, the particle lateral velocity can be predicted by calculating the slope of the straight line for each particle size. The resulted points were fitted (Figure 7) using Origin Lab 8.5 software. The high transverse velocities of large particles explain the short time they took to settle on the wall.

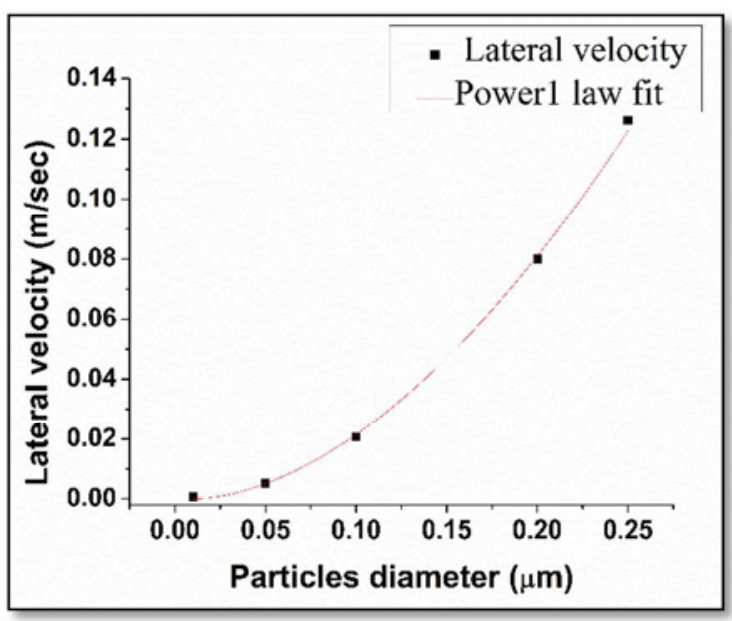

Figure 7: particles size effect on particle lateral velocity 
From the mentioned Figures, the threshold of particle diameters that affected by inertial forces was defined by Stokes number (equation 8). From this equation, the Stokes number is directly proportional to the square of particle diameter and decreasing the particle diameter (other parameters constant) will lower Stokes number.

Figure 8 confirmed that the highest Stokes number around 1.4E-3 observed from particles with $2.5 \mathrm{E}-7 \mathrm{~m}$ diameter, caused the most significant particle/fluid streamlines mismatch which; eventually, induced large particles to concentrate at the fiber wall.

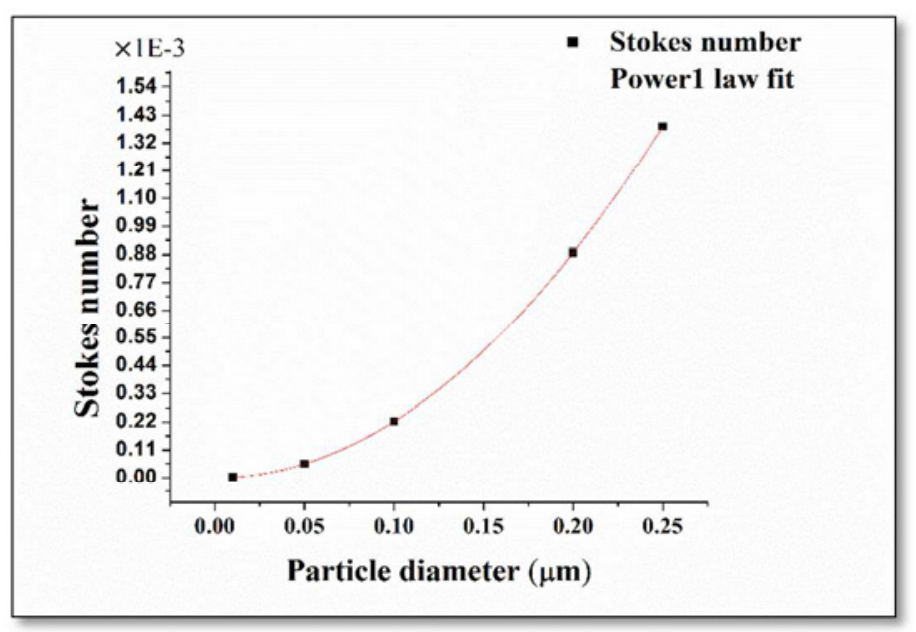

Figure 8: particle size effect on Stokes number

Finally, the relationship between Stokes number and the lateral shift is shown in Figure 9. It is very obvious that the particles lateral velocity increases linearly with increasing Stokes number. In addition, the threshold for Stokes number after which a negligible lateral particle velocity occurred, was around 2.2E-4. This means that particles having a diameter less than 1.0E-7 m were unable to cross the streamlines. Bec [48] simulation results showed that there was a critical value of Stokes number around $10^{/ 4}$ in which particles clustering happened. 


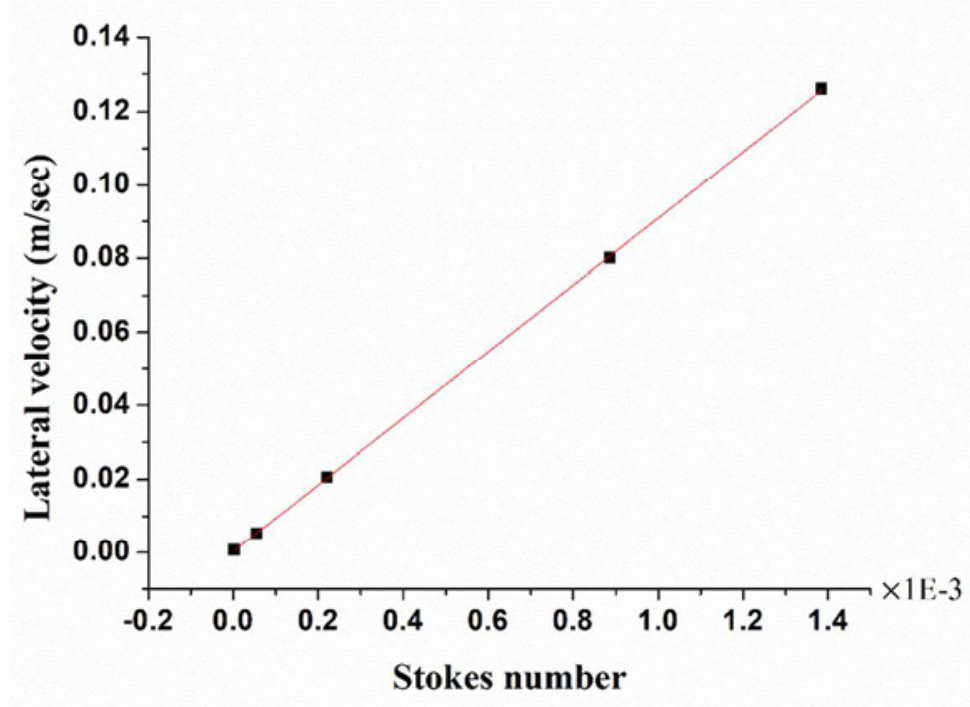

Figure 9: Stokes number influence on particles lateral velocity

\section{Conclusions}

A hybrid ceramic nano/fibers with controlled phase dispersion was performed using electrospinning of mixed binary system. The system consists of PAN polymer and silicon nano/ particles. To track the particle dispersion process, TEM characterization was carried out to visualize particles size and their distribution which followed by comutional study using COMSOL Multiphysics. Both experimental and numerical results showed that the larger silicon particles were located on the fiber surface and; eventually, the smaller particles concentrated at the core. The larger particles have higher inertial forces as compared with the smaller ones which enable them to migrate to a different locations within the fiber. In addition, it found the threshold for particle size to make the inertial effect effective was around $1.0 \mathrm{E}-7 \mathrm{~m}$. The threshold for Stokes number was found to be around 2.2E-4 with a critical particle size of 1.0E 7 $\mathrm{m}$ in diameter. The results demonstrated a novel way for the fabrication of PAN/Si ceramic nano/fibers with a gradient of particle size and properties from the skin to the core.

\section{References}

[1] Ji, L.; Jung, K.H.; Medford, A. J.; Zhang, X. Electrospun Polyacrylonitrile Fibers with Dispersed Si Nanoparticles and their Electrochemical Behaviors after Carbonization. $J$. Mater. Chem. 2009, 19, 4992/4997.

[2] Silva,A. N. R.; Silva, Maria, L. P. Silicon Compound Inclusion on PAN Nanofibers. 1st CSMVA \& XXXV CBRAVIC, Natal - Rio Grande do Norte 2014.

[3] Roy, J.; Chandra, S.; Das, S.; Maitra, S. Oxidation Behaviour of Silicon Aarbide /a 
Review. Rev. Adv. Mater. Sci. 2014, 38, 29/39.

[4] Hou, X.; Chou, K. Model of Oxidation of SiC Microparticles at High Temperature. Corros. Sci. 2008, 50, 2367-2371.

[5] Quanli, J.; Haijun, Z.; Suping, L.; Xiaolin, J. Effect of Particle Size on Oxidation of Silicon Carbide Powders. Ceram. Int. 2007, 33, 309/313.

[6] Balzer, C.; Armstrong, M.; Shan, B.; Huang, Y.; Liu, J.; Mu, B. Modeling Nanoparticle Dispersion in Electrospun Nanofibers. Langmuir 2018, 34,1340-1346.

[7] Shields, C. W.; Reyes, C. D.; López, G. P. Microfluidic Cell Sorting: A review of the Advances in the Separation of Cells from Debulking to Rare Cell Isolation. Lab Chip. 2015, $15,1230-1249$.

[8] Chatterjee, A. Size/Dependant Separation of Multiple Particles. Master thesis University of Cincinati, School of Electronics and Computing Systems, 2011.

[9] Yang, L. J.; Banada, P. P.; Chatni, M. R.; Lim, K. S.; Bhunia, A. K.; Ladisch, M.; Bashir, R. A. Multifunctional Micro/fluidic System for Dielectrophoretic Concentration Coupled with Immuno/Capture of Low Numbers of Listeria Monocytogenes. Lab Chip. 2006, 6, 896-905.

[10] Pamme, N.; Manz, A. On/Chip Free/Flow Magnetophoresis: Continuous Flow Separation of Magnetic Particles and Agglomerates. Anal. Chem. 2004, 76, 7250-7256.

[11] Macdonald, M. P.; Spalding, G. C.; Dholakia, K. Microfluidic Sorting in an Optical Lattice. Nature, 2003, 426, 421-424.

[12] Ladavac, K.; Kasza, K.; Grier, D. G. Sorting Mesoscopic Objects with Periodic Potential Landscapes: Optical Fractionation. Phys. Rev. E: Stat., Nonlinear, Soft Matter Phys.

$200470(1)$.

[13] Deng, T.; Prentiss, M.; Whitesides, G. M. Fabrication of Magnetic Microfiltration Systems Using Soft Lithography. Appl. Phys. Lett. 2002, 80, 461/463.

[14] Yung, C. W.; Fiering, J.; Mueller, A. J.; Ingber, D. E. Micromagnetic-Microfluidic Blood Cleansing Device. Lab Chip 2009, 9, 1171/1177.

[15] Pamme, N. Continuous Flow Separations in Microfluidic Devices. Lab Chip. 2007, 7, 1644/ 1659.

[16] Sun, X.Y.; Shankar, R.; Börner, H. G.; Ghosh, T. K.; Spontak, R. J. Field/Driven Biofunctionalization of Polymer Fiber Surfaces during Electrospinning. Adv. Mater. 2007 19, 87-91.

[17] Bonino, C. A.; Efimenko, K.; Jeong, S. I.; Krebs, M. D.; Alsberg, E.; Khan S. A. Three/ Dimensional Electrospun Alginate Nanofi ber Mats via Tailored Charge Repulsions. small. 2012, 8, 1928/1936.

[18] Kanbar, J. N. Hydrodynamic Focused Passive Separation under Continuous Flow in a Microfluidic Chip, master thesis. 2012, California Polytechnic State University.

[19] Tsutsui, H.; and Ho, C.M. Cell Separation by non/Inertial Force Fields in Microfluidic Systems. Mech. Res. Commun. 2009, 36, 92-103. 
[20] Szczech, J. R.; Jin, S. Nanostructured Silicon for High Capacity Lithium Battery Anodes. Energy Environ. Sci. 2010, 4, 56/72.

[21] Park, J.S; Jung, H. Multiorifice Flow Fractionation: Continuous Size/Based Separation of Microspheres Using a Series of Contraction/Expansion Microchannels. Anal Chem 2009, 81 8280-8288.

[22] Bec, J. Multifractal Concentrations of Inertial Particles in Smooth Random Flows. J. Fluid Mech. 2005, 528, 255/77.

[23] Uyar, T.; Kingshott, P.; Besenbacher, F. Electrospinning of CyclodextrinPseudopolyrotaxane Nanofibers. Angew. Chem., Int. Ed. 2008, 47, 9108 - 9111.

[24] Yang, D.; Liu, X.; Jin, Y.; Zhu, Y.; Zeng, D.; Jiang, X.; Ma, H. Electrospinning of Poly(Dimethylsiloxane) /Poly(Methyl Methacrylate) Nanofibrous Membrane: Fabrication and Application in Protein Microarrays. Biomacromolecules 2009, 10, 3335/ 3340.

[25] Crespy, D.; Friedemann, K.; Popa, A. M. Colloid/Electrospinning: Fabrication of Multicompartment Nanofibers by the Electrospinning of Organic or/and Inorganic Dispersions and Emulsions Macromolecular 2012, 33, 1978-1995.

[26] Narisawa, M.; Yasuda, H.; Mori, R.; Mabuchi, H.; Oka, K.; Kim, Y. Silicon Carbide Particle Formation from Carbon Black / Polymethylsilsesquioxane Mixtures with Melt Pressing. J. Ceram. Soc. Jpn. 2008, 116, 121/125.

[27] Qing/Song, M.; Zhao/Hui, C.; Wen/Wei, Z.; Hai/Feng, H. Effects of Pyrolysis Processes on Microstructure and Mechanical Properties of $\mathrm{C}_{\mathrm{f}} / \mathrm{Si} / \mathrm{O} / \mathrm{C}$ Composites Fabricated by Preceramic Polymer Pyrolysis. Ceram. Int. 2005, 31, 305-314.

[28] Jin, Y/J.; Kim, Y/W. Low Temperature Processing of Highly Porous Silicon Carbide Ceramics with Improved Flexural Strength. J. Mater. Sci. 2010, 45, 282-285.

[29] Odeshia, A. G.; Mucha, H.; Wielage, B. Manufacture and Characterisation of a Low Cost Carbon Fibre Reinforced C/SiC Dual Matrix Composite. Carbon. 2006, 44, 1994-2001.

[30] Lamouroux, F.; Bertrand, S.; Pailler, R.; Naslain, R.; Cataldi, M. Oxidation/Resistant Carbon/Fiber/Reinforced Ceramic/Matrix Composites. Compos. Sci. Technol. 1999, 59, 1073-1085.

[31] Rocha, R. M.; Cairo, C. A. A.; Graça, M. L. A. Formation of Carbon Fiber/Reinforced Ceramic Matrix Composites with Polysiloxane/Silicon Derived Matrix. Mater. Sci. Eng. A 2006, 437, 268-273.

[32] Yao, J.; Bastiaansen, C. W. M. ; Peijs, T. High Strength and High Modulus Electrospun Nanofibers. Fibers. 2014, 2, 158/186.

[33] Huang, C.; Chen, S.; Lai, C.; Reneker, D. H.; Qiu, H.; Ye, Y.; Hou, H. Electrospun Polymer Nanofibres with Small Diameters. Nanotechnology. 2007, 17, 1558-1563.

[34] Huang, Z.M.; Zhang, Y.Z.; Kotaki, M.; Ramakrishna, S. A review on Polymer Nanofibers by Electrospinning and their Applications in Nanocomposites. Compos. Sci. Technol. 2003, $63,2223 / 2253$.

[35] Beachley, V.; Wena, X. Effect of Electrospinning Parameters on the Nanofiber Diameter and Length. Mater. Sci. Eng., C., 2009, 29, 663/668. 
[36] Saja, A.; Lafdi, K.; Liu,Y.; Le Coustumer, P. Fabrication of Ceramic Nanofibers using Polydimethylsiloxane and Polyacrylonitrile Polymer Blends. J. Appl. Polym. Sci. 2018, $135,45967$.

[37] Liu, C.; Lafdi, K. Fabrication and Characterization of Carbon Nanofibers from Polyacrylonitrile/Pitch Blends. J. Appl. Polym. Sci. 2017, 134, 45388.

[38] Kim, H. J.; Um I. C. Relationship between Rheology and Electro/Spinning Performance of Regenerated Silk. Korea-Aust Rheol. J. 2014, 26, 119/125.

[39] Mit/uppatham, C.; Nithitanakul, M.; Supaphol, P. Ultrafine Electrospun Polyamide/6 Fibers:Effect of Solution Conditions on Morphology and Average Fiber Diameter Macromol. Chem. Phys. 2004, 205, 2327/2338.

[40] Kancheva, M.; Toncheva, A.;Manolova, N.; Rashkov, I. Enhancing the Mechanical Properties of Electrospun Polyester Mats by Heat Treatment. Express. Polym. Lett. 2015, 9, 49-65.

[41] Microfluids Moduls, Version 5, COMSOL, Inc.

[42] Bellan, L. M.; Craighead, H. G. Direct Measurement of Fluid Velocity in an Electrospinning jet using Particle Image Velocimetry. J. Appl. Phys. 2007, 102, doi.org/10.1063/1.2799059.

[43] Menon, A.; Somasekharan, K. Velocity, Acceleration \& Jerk in Electrospinning. The Internet Journal of Bioengineering. 2008, 4(2).

[44] Particle Tracing Module, Version 5, COMSOL, Inc.

[45] Malley, P. O. Trajectories of Inertial Particles and Fluid Elements. Haverford College, Haverford PA, thesis, 2008.

[46] Nain, R.; Singh, D.; Jassal, M.; Agrawal, A.K. Zinc Oxide Nanorod Assisted Rapid Single/ Step Process for the Conversion of Electrospun Poly(acrylonitrile) Nanofibers to Carbon Nanofibers with a High Graphitic Content. Nanoscale. 2016, 8, 4360/4372.

[47] Newsome, T. E.; Olesik, S. V. Electrospinning Silica/Polyvinylpyrrolidone Composite Nanofibers. J. Appl. Polym. Sci. 2014, 131(21),

[48] Bec, J. Multifractal Concentrations of Inertial Particles in Smooth Random Flows J. Fluid Mech. 2005, 528, 255-277. 